\title{
Therapeutic Nutritional Knowledge regarding Cardio-Vascular Diseases among Nursing Students
}

\author{
Satyam Prakash*1, Khushbu Yadav² \\ Department of Biochemistry \\ Janaki Medical College Teaching Hospital, Janakpurdham, Nepal
}

${ }^{1 *}$ Assistant Professor, Department of Biochemistry, Janaki Medical College Teaching Hospital, Janakpurdham

2 Medical Microbiologist \& Lecturer, Krishna Medical Technical Research Center, Janakpurdham

\begin{abstract}
Background and Objectives: The accountability of nurses for nutritional care and best nutritional practices in nutritional management has been shown to improve patient outcomes at hospitals. Several studies had been conducted before to explore the level of nutritional knowledge among nurses in different countries but there is paucity of data among nursing students. Therefore, the present study was designed to focus on bachelor level nursing students about the therapeutic nutritional knowledge towards CVDs.

Material and Methods: A cross sectional descriptive study was conducted among 97 nursing students studying in B.Sc. nursing and PBBN programme. Random sampling technique was used. Structured questionnaire was distributed to each participant to choose the most correct answer. The collected data was entered in Microsoft Excel for analysis. The level of knowledge was assessed on the basis of percentage score.
\end{abstract}

Results: Out of total students, $42 \%$ were less than or equal to 20 years and $58 \%$ were greater than 20 years. Most of the students were from Dhanusha district. Almost all respondents had heard about the different types of diet, CVD (98.96\%) but 1.03\% respondent was not familiar with CVD. 93.81\% respondents knew high blood cholesterol increases the incidence of heart disease and 85.56\% responded that caffeinated beverage is harmful for myocardial infarction. The poor knowledge was found about good fats and bad fats among respondents.

Conclusion: The basic information regarding CVDs was significant but the therapeutic nutritional knowledge among the nursing students was found to be satisfactory. Therefore, the improvement in the curriculum of undergraduate nursing courses is necessary regarding the proper therapeutic nutritional knowledge for its integration into health services effectively at hospitals.

Key Words: Cardiovascular disease, Knowledge, Nutrition, Satisfactory, Therapeutic diet

INRODUCTION

Despite of recent advances in diagnostic and therapeutic technologies, cardiovascular diseases (CVDs) are accountable for nearly half of all deaths in the developed and developing countries [1]. It is expected to be the world's number one cause of death or 
disability by the year 2020 [2]. Nepal is in front of a double burden of disease, both communicable and non-communicable diseases. But, CVDs is being the most common diseases as a major cause of death nowadays [3]. CVD was first documented in the 1970s with cases of myocardial infarction [4] followed by occasional publications on risk factors such as hypertension and smoking in the different Nepalese and Indian journals [58].

World Health Organization estimates that one billion people in the world are overweight and about 300 million people are obese. These numbers can enhance the incidence of type 2 diabetes and hypertension that are recognized as the main CVDs risk factors. Various risk factors such as physical inactivity, abdominal obesity, hyperlipidemia, and/or smoking, sedentary lifestyle, urbanization and modernization have the potential effect in advancement of CVDs events. Considering the fact that CVD is a mortal disease, the role of the individual's attitude and behavior is significant in the occurrence of cardiovascular diseases [1]. Early detection, education, food behavior and high degree modification in life style would be more efficient and cost-effective in improvement and prevention against cardiovascular diseases $[9,10]$.

As there is an absence of a routine surveillance or registry system, the actual burden and trend of CVDs in Nepal is unknown. But, combined data from various sources indicates that the CVDs problem is common and its risk factors are mounting rapidly [11]. There is strong relationship between education presentation methods and educational value in scientific substructures of each society. So, Knowledge based comprehensive competence and conducting studies for evaluating basic knowledge and attitude have a great importance [12]. Nurses can act as crucial communicators of this information to individuals recognized with the distinguished risk factors of diseases. Nurses can play an important role in specifying dietary patterns and making healthy dietary selections in reducing CVDs. The important strategies for prevention and control of CVDs are only possible with beneficial education and proper guidance in reducing risk factors [9].

Although, the last few decades has seen more publications of CVD studies including reports of hospital audits on CVDs, biochemical studies on blood sugar and lipids, and a few more on interventional cardiology as well [13]. But, there is a dearth of public health personnel trained in CVDs having adequate nutritional knowledge and thus there is an urgent need to groom staff in this sector. The rapid proliferation of scientific knowledge puts nutrition in competition with other medical education topics.

Most of the studies were conducted to investigate the level of nutritional knowledge of nurses in different countries [14, 15] but there is scarceness of data among nursing students. Therefore, the present study was carried out to assess the therapeutic nutritional knowledge regarding cardiovascular diseases among nursing students of Krishna Medical Technical Research Center, Janakpurdham located in Dhanusha district of Nepal. The results of this study may be fruitful in health politics, health-care providing officials and Ministry of health to improve health education programs and evaluation of the effectiveness of interventional programs in nursing colleges and production of qualitative nursing professionals. 


\section{MATERIAL AND METHODS}

\section{Study Design}

This descriptive cross sectional study was carried in 2016 AD at Krishna Medical Technical Research Center (KMTRC), Janakpurdham which is located in Dhanusha district of Nepal. A total of 97 students were enrolled in this study and random sampling technique was used.

The students who were willing to participate and filled the questionnaire appropriately were included. Those students who were not available at the time of data collection, teaching faculties and non-teaching staffs were excluded. A written letter was obtained from the institution and also verbal informed consent was taken from each participant explaining the objective of the study prior to data collection.

\section{Data collection and Processing}

Students in a class were given a brief description about the importance of study. Structured questionnaire was distributed to each participant to choose the most correct answer. The data collection was performed by the members of this research group and was cross checked by one another for any missed information for accuracy, utility and completeness. The collected data was entered in Microsoft Excel. The questionnaire consists of two major sections.

Section A: Questions related to general information of the participants.

Section B: Questions related to the therapeutic nutritional knowledge regarding CVD and its risk factors. The knowledge tools consisted of 22 items. Each items had 3 options with one correct answer. Each correct answer contains 'one score' and wrong answer as 'Zero score'. The knowledge was categorized on the basis of percentage scores obtained.

Table 1: Percentage knowledge score

\begin{tabular}{|c|c|c|}
\hline $\begin{array}{c}\text { Level of } \\
\text { knowledge }\end{array}$ & $\begin{array}{c}\text { Percentage } \\
\text { (\%) }\end{array}$ & Actual score \\
\hline Poor & $0-33$ & $0-7$ \\
\hline Average & $33-65$ & $8-13$ \\
\hline Good & $66-100$ & $14-20$ \\
\hline
\end{tabular}

\section{RESULTS}

\section{Age-wise distribution of total study population}

A total of 97 nursing students were enrolled in this study. Out of total students, 41 (42\%) were less than or equal to 20 years and 56 (58\%) were in greater than 20 years. The results are shown in figure 1.

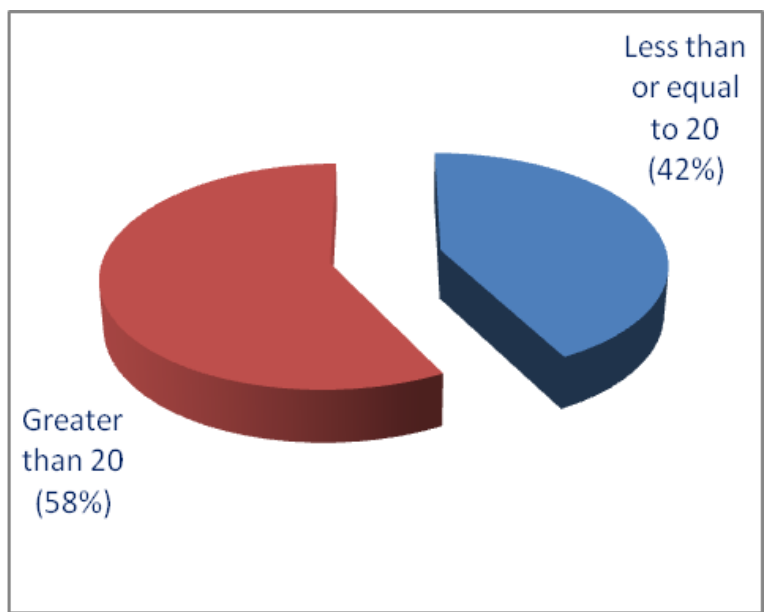

Figure 1: Pattern of age group in study population

\section{District wise distribution of all respondents}

Figure 2 shows that 15 (16\%), 14 (14\%), 50 (52\%), 2 (2\%), 8 (8\%), $2(2 \%), 3(3 \%)$ and 3 (3\%) respondents were from Siraha, Mohattari, Dhanusha, Tanahu, Saptari, Morang, Sunsari and others respectively. 


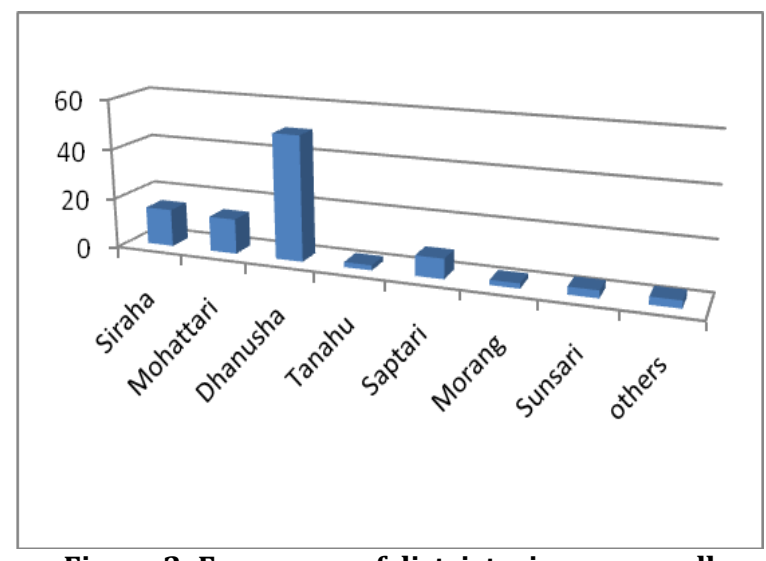

Figure 2: Frequency of district wise among all respondents

\section{The overall knowledge about CVD and its inter-related factors}

Figure 3 shows poor knowledge among respondents about the source of nutrients, the therapeutic nutritional knowledge regarding CVD was average and the basic information about CVD was good.

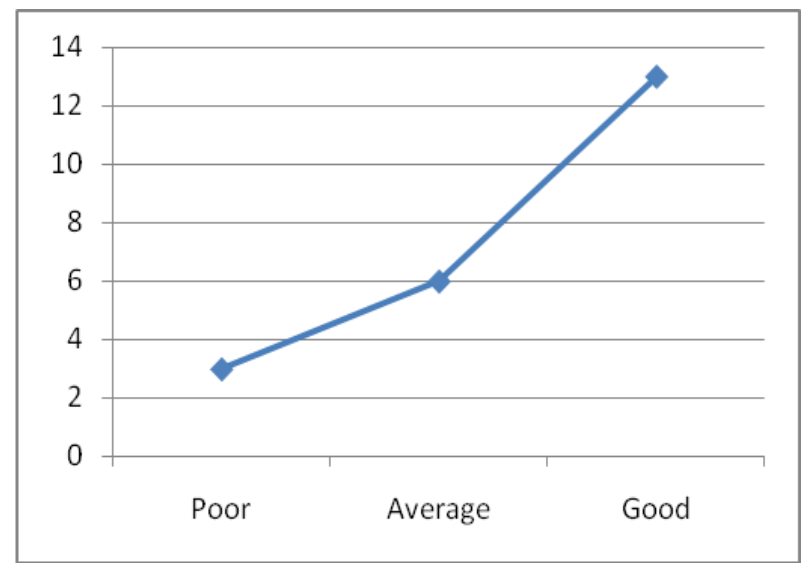

Figure 3: The knowledge score among all respondents

\section{Knowledge regarding cardiovascular disease}

Almost all respondents had heard about the different types of diet, CVD and its relationship between hypertension \& obesity but $1.03 \%$ respondent was unknown with CVD. Most of the respondents were familiar that high blood cholesterol increases the incidence of heart disease with 93.81\%. $85.56 \%$ respondents had knowledge that caffeinated beverage is harmful for myocardial infarction. But, only $12.37 \%$ respondents were known to the fact that less than $300 \mathrm{mg}$ cholesterol is recommended for CVD patients. The results are shown in table 2.

\section{DISCUSSION}

Cardiovascular diseases are the most significant chronic disease commonly seen in individuals with metabolic syndrome including hypertension, hyperlipidemia, heart failure and elevated fasting blood glucose [16] leading to the common cause of premature death and disability around the globe [17]. Standard clinical practice guidelines often fail to face the unique challenges in CVDs and its planning and management. Nowadays, the practice of evidence-based medicine compels the high risk for cardiovascular disease which includes lifestyle practices, physical activity, behaviors, heavy smoking [18], excessive use of alcohol, cocaine, drugs that elevate blood pressure and damage the heart [19], poorly controlled hypertension, hypercholesterolemia, diabetes [20], poor diet, visceral obesity $[18,21]$, chronic emotional or psychological stress [18], limited access to preventive and remedial health care [19] and periodontitis [22].

Nutritional care is considered as an integral part of the primary care provided to hospitalized patients. Nurses are in an ideal position to provide nutritional knowledge and sustain the patient's motivation in cardiovascular diseases (CVDs) and its risk factors. An effective communication and cooperation among professionals involved in 
Table 2: Knowledge regarding cardiovascular disease

\begin{tabular}{|c|c|c|c|c|}
\hline \multicolumn{4}{|c|}{ Table 2: Knowledge regarding cardiovascular disease } & \multirow{2}{*}{$\begin{array}{c}\mathbf{N}=97 \\
\text { Level of } \\
\text { knowledge }\end{array}$} \\
\hline Knowledge & Yes (\%) & No (\%) & Don't know (\%) & \\
\hline Diet & $97(100)$ & 0 & 0 & Good \\
\hline Balanced diet & $97(100)$ & 0 & 0 & Good \\
\hline Therapeutic diet & $97(100)$ & 0 & 0 & Good \\
\hline $\begin{array}{l}\text { Difference between balanced diet \& } \\
\text { therapeutic diet }\end{array}$ & $97(100)$ & 0 & 0 & Good \\
\hline Cardiovascular disease (CVD) & $96(98.96)$ & $1(1.03)$ & 0 & Good \\
\hline $\begin{array}{c}\text { Relationship between hypertension \& } \\
\text { obesity for CVD }\end{array}$ & $97(100)$ & 0 & 0 & Good \\
\hline $\begin{array}{l}\text { Low sodium diet is recommended for } \\
\text { treatment of hypertension }\end{array}$ & $86(88.65)$ & $9(9.27)$ & $2(2.06)$ & Good \\
\hline Diuretics patient lacks potassium & $49(50.51)$ & $44(45.36)$ & $4(4.12)$ & Average \\
\hline $\begin{array}{l}\text { Calcium decreases the risk of } \\
\text { hypertension }\end{array}$ & $38(39.17)$ & $53(54.63)$ & $6(6.18)$ & Average \\
\hline $\begin{array}{l}\text { Low saturated fat decreases the risk of } \\
\text { coronary artery disease (CAD) }\end{array}$ & $87(89.69)$ & $10(10.30)$ & 0 & Good \\
\hline $\begin{array}{l}\text { High blood cholesterol increases the } \\
\text { incidence of heart disease }\end{array}$ & $91(93.81)$ & $6(6.18)$ & 0 & Good \\
\hline $\begin{array}{l}\text { Trans fats (margarine) is recommended } \\
\text { for CVD }\end{array}$ & $51(52.57)$ & $40(41.23)$ & $6(6.18)$ & Average \\
\hline $\begin{array}{c}\text { Fish oil is beneficial to reduce } \\
\text { hyperlipedemia }\end{array}$ & $64(65.97)$ & $31(31.95)$ & $2(2.06)$ & Average \\
\hline $\begin{array}{l}\text { Caffeinated beverage is harmful for } \\
\text { myocardial infraction }\end{array}$ & $83(85.56)$ & $13(13.40)$ & $1(1.03)$ & Good \\
\hline Low fat milk is to reduce total fat intake & $68(70.10)$ & $28(28.86)$ & $1(1.03)$ & Good \\
\hline $\begin{array}{l}\text { Palm oil contains high amount saturated } \\
\text { fat }\end{array}$ & $19(19.58)$ & $78(80.41)$ & 0 & Poor \\
\hline $\begin{array}{l}\text { Saturated fatty acids is not recommended } \\
\text { for CAD }\end{array}$ & $57(58.76)$ & $34(35.05)$ & $6(6.18)$ & Average \\
\hline Margarine is not a source of cholesterol & $27(27.83)$ & $66(68.04)$ & $4(4.12)$ & Poor \\
\hline $\begin{array}{c}<300 \mathrm{mg} \text { cholesterol is recommended for } \\
\text { CVD }\end{array}$ & $12(12.37)$ & $79(81.44)$ & $6(6.18)$ & Poor \\
\hline $\begin{array}{l}\text { Chicken breast is not restricted for } \\
\text { hyperlipedemia patients }\end{array}$ & $35(36.08)$ & $44(45.36)$ & $18(18.55)$ & Average \\
\hline $\begin{array}{l}\text { Roll cake is the incorrect way to lower fat } \\
\text { intake }\end{array}$ & $82(84.53)$ & $13(13.40)$ & $2(2.06)$ & Good \\
\hline
\end{tabular}

patient's medical care are important for successful nutritional management. In this study, altogether 97 nursing students were assessed for therapeutic nutritional knowledge regarding CVDs. Of total, most of the participants were in greater than 20 years and from Dhanusha district followed by Siraha and others. The probable reason for the dominance of students from this district may be due to locality of study area in
Janakpurdham located at Dhanusha district which is also considered as an educational hub for different undergraduate and postgraduate academic courses in Terai-Madhesh of Nepal. Also, this may be due to the convenience of guardians for the continuation of further study of female candidates at the local level.

Even though the advancement found in recent decades in terms of pharmacological 
management of CVD, therapeutic nutritional knowledge still plays a key role in primary and secondary prevention of disease. The present study revealed that almost all respondents had heard about the different types of diet, CVD and relationship between hypertension \& obesity for CVD. The possibility of such type of result may be due to the fact that diet is the customary amount which is taken by an individual everyday for healthy life and preservation of body. Also, diet is considered as the primary tools for growth and development.

Nowadays, hypertension is common among most of the individuals. Hypertension, simply known as high blood pressure is generally elevated by consuming sodium diet constituents. It confers the highest attributable risk to deaths from cardiovascular disease [23] which is evident even in childhood with elevated blood pressure predicting hypertension in adulthood. The adverse effects of elevated blood pressure in childhood on vascular structure and function, specifically left ventricular hypertrophy are already apparent in youth [24]. In Nepal, study conducted by Shankar et al. 2007, with regard to the knowledge about heart attack and hypertension among individuals attending a cardiac camp showed that the respondents were aware of the basic facts regarding myocardial infarction and hypertension. Conversely, lack of knowledge was noted, the knowledge scores for hypertension especially were significantly lower among the respondents [25].

The physical, medical, economic and societal impact of the obesity epidemic is surprising which noticeably affect general population [26]. The long-term effect of obesity is associated with increase in atherosclerotic cardiovascular disease and its inherent physical consequences [27]. The development of obesity-induced hypertension is multifactorial and includes an increase in peripheral vascular resistance via endothelial dysfunction, activation of the sympathetic nervous system, direct and indirect renal effects, sleep apnea, and other vasoactive effects of peptides released from adipocytes [17].

This study highlights that $88.65 \%$ respondents had good knowledge about low sodium diet recommendation for the treatment of hypertension. A similar type of finding was also obtained in the study conducted by Naseem et al 2013 [28]. The good knowledge towards this may be due to increasing number of hypertension cases day by day. Another likely possibility may be that their parents and relatives may be suffering from high blood pressure and may have more consciousness towards this disease. It may also be due to the inclusion of nutrition and dietetics in their curriculum and sincerity during lectures in the classroom.

This study depicts that $50.51 \%$ and $39.17 \%$ students had average knowledge about diuretics patient lacks potassium and calcium decreases the risk of hypertension. Similarly, $52.57 \%, \quad 65.97 \%, \quad 58.76 \%$ and $36.08 \%$ respondents had average knowledge of transfats (margarine) is recommended for CVD, fish oil is beneficial to reduce hyperlipidemia, saturated fatty acids is not recommended for CAD and chicken breast is not restricted for hyperlipidemia patient. This may be due to the less usage of Margarine in daily diet. Margarine which is made from vegetable oils helps to reduce low-density lipoprotein (LDL) or "bad" cholesterol. The effect of dietary saturated fat on plasma lipoproteins most strongly affect CVD risk elevated with LDL- 
cholesterol concentrations. Replacement of saturated fat with polyunsaturated fat has been shown to decrease total, LDL and HDL cholesterol [29].

The present study signifies that the respondents had good knowledge about low saturated fat decreases the risk of coronary artery disease (89.69\%), high blood cholesterol increases the incidence of heart disease (93.81\%), caffeinated beverage is harmful for myocardial infarction (85.56\%), low fat milk is to reduce total fat intake $(70.10 \%)$ and roll cake is the incorrect way to lower fat intake (84.53\%). The probable reason may be acknowledged with the fact that fat is an important part of a healthy diet and it's more important to focus on eating beneficial "good" fats and avoiding harmful "bad" fats.

For the implementation of a diet targeted at reducing cardiovascular events, it is necessary to know the nutritive value of foods. Randomized clinical trials have also shown that adopting a diet with very low saturated fat reduces cholesterol levels and cardiovascular events [30]. This study also revealed that poor knowledge among respondents about palm oil contains high amount saturated fat, margarine is not a source of cholesterol and less than $300 \mathrm{mg}$ cholesterol is recommended for CVD was found $19.58 \%, \quad 27.83 \%$ and $12.37 \%$ respectively. This may be due to little information about the effects of saturated fat on CVD risk factors.

But, in a study conducted by Naseem et al 2013 reported that high percentages of participants believed that cardiovascular diseases patients should limit their intake of saturated fat (87\%), trans fat (50\%), and caffeinated beverages (88\%). Although 69\% of nurses agreed that high blood cholesterol increases the incidence of heart disease [28] which is not in accord with this study.

\section{CONCLUSION}

Beside tremendous advances in cardiac care and curative treatment in CVDS, there has been a recent shift towards preventive measures to address the development of risk factors. As the knowledge base in medicine increases, there is considerable competition for nutritional knowledge in classroom and hospitals. The present study concludes that the nursing students of KMTRC had good basic knowledge about CVD but the therapeutic nutritional knowledge of CVD and its inter-related factor was found average.

It is evident from this study that teaching and learning activities of nutrition and dietetics is proper and students are conscious towards this subject at KMTRC and should be promoted more effectively for better results in future. This emphasizes the appropriate methods for translation and dissemination of knowledge must be determined.

The necessity of improving the curriculum of undergraduate nursing courses regarding the nutrition issues and its importance should be addressed properly. There should be continuing training educational programme by health care professionals to school, colleges \& community level about the risks of CVDs. The prevention and promotion of healthy nutritional habits would be helpful in promoting nursing students and future nurses actively involving in nutritional management of CVD patients and can change the social and physical environment creating links with the community. 


\section{LIMITATION}

The limitation of this study was that most of the students in this study were from same geographical background with small sample size and cannot be generalized to the entire nursing students of Dhanusha district.

\section{ACKNOWLEDGEMENT}

Authors wish their heartfelt thanks to B.Sc $1^{\text {st }}$ year nursing students ( $5^{\text {th }}$ Batch) of Krishna Medical Technical Research Centre (KMTRC), Janakpur, Nepal for their mutual co-operation and consistent support during data collection.

\section{AUTHOR'S CONTRIBUTION}

SP- designed the concept of study, inscription of first draft and critically reviewed and final approval of the manuscript; KY- Data Collection and descriptive analysis, reviewed literatures, preparation and decisive revision of the final manuscript.

\section{SOURCE OF SUPPORT: None}

CONFLICT OF INTEREST: Authors declared that there is no conflict of interest.

\section{REFERENCES}

1. World Health Organization. Global Health Risks: Mortality and burden of disease attributable to selected major risks, World Health Organization, Geneva 2009.

2. Gaziano TA. Reducing the growing burden of cardiovascular disease in the developing world. Health Aff 2007; 26:13- 24.

3. Ministry of Health and Population. Nepal NonCommunicable Diseases Risk Factors Survey 2007. Kathmandu, Nepal: Ministry of Health and Population, 2009.

4. Pandey MR. Myocardial infarction in Nepal. Indian Heart J 1970; 22: 73-82.

5. Pandey MR. Hypertension in Nepal. Bibl Cardiol 1987; 42: 68-76.

6. Pandey MR, Shrestha NK, Upadhyaya AB et al. Prevalence of smoking in a rural community of
Nepal. World Smoking and Health 1981; 33: 35.

7. Pandey MR, Venkatramaiah SR, Neupane RP et al. Epidemiological study of tobacco smoking behaviour among young people in a rural community of the hill region of Nepal with special reference to attitude and beliefs. Community Med 1987; 9: 10-12.

8. Pandey MR, Neupane RP, Gautam A. Epidemiological study of tobacco smoking behaviour among adults in a rural community of the hill region of Nepal with special reference to attitude and beliefs. Int J Epidemiology 1988; 17: 535-41.

9. Gilski DJ. Risk Evaluation in Action for Cardiovascular Health. Critical Care Nurse 2005: 25(1); 26-37.

10. Glanz K \& Bishop DB. The role of behavioral science theory in development and implementation of public health interventions. Annu Rev Public Health 2010; 31: 399-418.

11. Vaidya A, Pokharel PK, Nagesh $S$ et al. Prevalence of coronary heart disease in the urban adult males of eastern Nepal: a population-based cross-sectional study. Indian Heart J 2009; 61: 341-347.

12. Jones CA, Perera A, Chow M, Ho I, Nguyen J, Davachi S. Cardiovascular disease risk among the poor and homeless-What we know so far. Current Cardiology Reviews 2009; 5(1):69-77.

13. Rawat B, Rajbhandary S, Shrestha SK. First sixyears of primary percutaneous coronary intervention at Norvic International Hospital: patient profile, procedural efficiency and follow-up. Nepalese Heart Journal 2010; 7: 734.

14. Park KA, Cho WI, Song KJ, Lee YS, Sung IS and Choi-Kwon SM. Assessment of nurses' nutritional knowledge regarding therapeutic diet regimens. Nurse Education Today 2011;31(2): 192-197.

15. Crogan NL, Shultz JA and Massey LK. Nutrition Knowledge of Nurses in Long-Term Care Facilities. The Journal of Continuing Education in Nursing 2001; 32(4): 171-176.

16. Deen D. Metabolic Syndrome: Time for Action. American Family Physician; June 15, 2004. (www.aafp.org/afp/20040615/2875.html)

17. Kones R. Primary prevention of coronary heart disease: integration of new data, evolving views, revised goals, and role of rosuvastatin in management. A comprehensive survey. Drug Des Devel Ther 2011; 5: 325-80. 
18. McMahan S, Cathorallm M, Romero DR. Cardiovascular Disease Risk Perception and Knowledge: A Comparison of Hispanic and White College Students in a Hispanic-Serving Institution. Journal of Hispanic Higher Education 2007; 6: 5-18.

19. McCarey JM \& O'Connell JJ. Editorial: Health, housing, and the heart: Cardiovascular disparities in homeless people. Circulation 2005; 111: 2555-2556.

20. Lee TC, Hanlon JG, Ben-David J, Booth GL, Cantor WJ, Connelly PW et al. (2005). Risk factors for cardiovascular disease in homeless adults. Circulation 2005; 24;111(20):2629-35.

21. Getz GS \& Reardon CA. Nutrition and cardiovascular disease. (Arterioscler Thromb Vasc Biol 2007; 27: 2499-2506.

22. Friedewald VE, Kornman KS, Beck JD, Genco R, Goldfine A, Libby $P$ et al. The American Journal of Cardiology and Journal of Periodontology Editors' Consensus Report: Periodontitis and Atherosclerotic Cardiovascular Disease. J Periodontol July 2009; 80(7): 1021-1032.

23. Lopez AD, Mathers CD, Ezzati M, Jamison DT, Murray CJ. Global and regional burden of disease and risk factors, 2001: Systematic analysis of population health data. Lancet 2006;367:1747-57.

24. Hanevold C, Waller J, Daniels S, Portman R, Sorof J. The effects of obesity, gender, and ethnic group on left ventricular hypertrophy and geometry in hypertensive children: A collaborative study of the International Pediatric Hypertension Association. Pediatrics 2004; 113:328-33.

25. Shankar PR, Partha P, Shenoy N, Chandrasekhar TS, Dubey AK. Knowledge about heart attack and hypertension among individuals attending a cardiac camp in Pokhara city. Kathmandu Univ Med J 2007; 5: 273-8.

26. Poirier P, Giles TD, Bray GA, et al. Obesity and cardiovascular disease: pathophysiology, evaluation, and effect of weight loss: an update of the 1997 American Heart Association scientific statement on obesity and heart disease from the obesity committee of the Council on nutrition, physical activity, and metabolism. Circulation 2006; 113: 898-919.

27. Grundy SM. Obesity, Metabolic Syndrome, and Cardiovascular Disease. J Clin Endocrinol and Metabolism 2004; 89(6): 2595-2600.
28. Al-Shwaiyat MN, Sinjillawi BA, Al-Rethaiaa SA, Fahmy AA, Al-Saraireh MR, Aqel MM et al. Assessment of therapeutic nutritional knowledge of Jordanian nurses. Int J Nutri Food Sci 2013; 2(3): 142-148.

29. Hodson L, Skeaff CM, Chisholm WA. The effect of replacing dietary saturated fat with polyunsaturated or monounsaturated fat on plasma lipids in free-living young adults. Eur J Clin Nutr 2001; 55: 908-15.

30. Leren P. The Oslo diet-heart study: elevenyear report. Circulation. 1970; 42 (5): 935-42.

\section{Correspondence to: \\ Satyam Prakash \\ Assistant Professor \\ Department of Biochemistry \\ Janaki Medical College Teaching Hospital \\ Tribhuvan University, Janakpur - 45600, Nepal \\ Email: sprakashy2424@gmail.com}

